\title{
Importance of Communication Cues in Music Performance according to Performers and Audience
}

\author{
Satoshi Kawase ${ }^{1}$ \\ ${ }^{1}$ Department of Music, Soai University, Osaka, Japan \\ Correspondence: Satoshi Kawase, Department of Music, Soai University, 4-4-1 Nankonaka Suminoe-ku, \\ Osaka-shi, Osaka 559-0033, Japan. Tel: 81-6-6612-5900. E-mail: satoshikawase.psy@gmail.com
}

Received: March 11, 2014

Accepted: April 16, $2014 \quad$ Online Published: May 20, 2014

doi:10.5539/ijps.v6n2p49

URL: http://dx.doi.org/10.5539/ijps.v6n2p49

\begin{abstract}
The present study was designed to investigate what types of communication cues performers and audience members regard as important during music performance. Our attempt differed from other studies in that it explored a holistic perspective of multiple cues in music performance through self-reports. The questionnaires provided a simple model of reciprocal communication flows among four roles, namely, performer, co-performer, audience, and co-audience member, as well as 10 types of communication cues, namely, facial expression, gaze, body movement, posture, touch, interpersonal distance, verbal information, attire, breath, and musical sound. A total of 86 performers and 149 audience members filled in the questionnaires. In referring to this model and imagining music performances, they rated the importance of communication cues according to their role as performers or audience members, situations (practice/performance). Performers selected the music genres that their performances usually play. Performers were also asked to draw stage positioning in music performance. The main findings are as follows: (1) Participants' roles as either performers or audience members affected their opinions about the importance of communication cues. In inter-performer communication, sound, gaze, body movement, facial expression, and breath were rated as highly important in both practice and performance. In performer-to-audience communication, musical sound, facial expression, and body movement were rated as highly important. (2) Participants regarded similar cues as important regardless of their role: senders and receivers of inter-performer and performer-to-audience communication. (3) Music genre (classical or popular) and situation (practice or performance) influenced participants' opinions about the importance of communication cues and stage positioning.
\end{abstract}

Keywords: ensemble performer, audience, communication cue, music performance, multimodal interaction, musical communication, coordination, music genre, stage positioning, practice

\section{Introduction}

In musical performance, we frequently see that performers and audience members employ multiple cues for communication. For example, conductors direct gestures to performers. Piano duo performers exchange eye contact with co-performers. Singers in popular music bands demonstrate gestures to audience members, who respond by mimicking their gestures. A large number of empirical studies have explored individual cues, such as sound, body movement, gaze, and facial expressions. Still, entire cues have rarely been discussed from a holistic perspective. Furthermore, despite their important suggestions, musical communication models do not provide all-inclusive views of musical cues.

Several questions thus arise. Do performers and audience members rank importance among these cues? Or do they regard these cues as equally significant? Do several cues exist to which performers pay attention but audience members do not? Or do both performers and audience members consider the same cues important? In the present study, we focused on these questions and proposed a model of integrative communication cues among participants in ensemble music. The present study differed from prior studies in that it examined the types of cues ensemble participants regard as important while considering multiple cues. We thus reviewed individual musical communication cues and models of musical communication in the available literature. 


\subsection{Inter-Performer Cues for Performance Coordination}

Ensemble musicians employ multifaceted cues for communication with co-performers: e.g., talk, sound, body movement, gaze, and breath. Verbal interaction among performers before a live performance is important for an ensemble in practice session. Effective communication among ensemble members enhances the quality of performance (Ginsborg, Chaffin, \& Nicholson, 2006; Ginsborg \& King, 2012).

Audio cues facilitate inter-performer coordination, particularly synchronization among performers (e.g., Loehr, Large, \& Palmer, 2011). Performers could synchronize with co-performers through sound alone while playing pieces without changing the tempo (Repp \& Penel, 2002). Anticipation or auditory imagery of performance is fundamental in an ensemble (Hubbard, 2010; Keller, Knoblich, \& Repp, 2007; Pecenka \& Keller, 2011).

Visual cues also enhance coordination among performers. Specifically, many recent studies have explored performers' body movements (Goebl \& Palmer, 2009; Keller \& Appel, 2010; Luck \& Toiviainen, 2006; Maduell \& Wing, 2007), including action simulation (Keller, 2012; Palmer, 2013). Keller and Appel (2010) elucidated that piano duo performers synchronize their body sway. Gazing behavior, such as eye contact has been found to make for a better performance (Kawase, 2009; Moran, 2010; Williamon \& Davidson, 2002). Kawase (2014) revealed that piano duo performers look toward co-performers shortly prior to the parts where tempo changes.

Breathing has also been found to influence inter-performer interaction. Nakamura (1995) demonstrated that the pianist's and the accompanist's breathing were synchronized during a pause in playing. Participants synchronized their breathing when communicating through drums (Kawase \& Nakamura, 2007).

\subsection{Cues for Performers' Conveyance of Intention or Audiences' Understanding of Performance}

Performer-audience interaction through multimodal cues also emerges during music performance: e.g., sound, body movement, posture, gaze, facial expressions, attire, attractiveness of appearance, and visibility of performers. Performers can convey their emotional intentions by utilizing audio cues (e.g., Gabrielsson \& Juslin, 1996; Juslin, 2001). Listeners, can decode the performers' intention via the acoustical parameters (e.g., Nakamura, 1987). Juslin $(2001,2005)$ clarified the process through which composers control mode, pitch, and other aspects; performers control tempo and sound level, etc.; and listeners perceive emotion.

If visual cues are available, they are also essential for encoding and decoding performances. Platz and Kopiez's (2012) meta-analysis demonstrated the significant impact of visual information on music perception compared with auditory information. Body movement serves for conveyance of emotion (e.g., Dahl \& Friberg, 2007; Krahé, Hahn, \& Whitney, in press) or the manner of expression (e.g., Davidson, 1993; Ohgushi, 2005: Vines, Krumhansl, Wanderley, Dalca, \& Levitin, 2011). The posture of conductors affects performance ratings (Van Weelden, 2002). Facial expression plays a role in the decoding of performers' expressions (Ohgushi \& Hattori, 1996; Thompson \& Russo, 2007; Wöllner, 2008). Performers' gaze toward audiences enhances the quality of the musical experience (Antonietti, Cocomazzi, \& Iannello, 2009). Performers' attire (Griffiths, 2008), attractiveness, and stage behavior (Wapnick, Mazza, \& Darrow, 1998) influence performance ratings by audience members. In appreciation of performances, audience members tended to consider visibility of the performers to be important when selecting their seats in a concert hall (Kawase, 2013).

\subsection{Models of Musical Communication}

Researchers have posited multiple models of musical communication between performers and audience members. Davidson (1997) created a model of interaction between multiple performers and multiple audience members. To explain the interaction among participants in a music performance, the present study referred to Davidson's model. In communication through sound, Kendall and Carterette (1990) proposed a model that illustrates how musical signals and related factors are directed by composers toward listeners by means of performers' playing. Juslin (2005) proposed the Expanded Lens Model (ELM) as a process through which composers control mode, pitch, etc.; performers control tempo, sound level, etc.; and audience members perceive emotion via acoustic cues. These two models mainly highlight the one-way communication from performer or composer to listener. In contrast, Hargreaves, MacDonald, and Miell (2005) proposed a reciprocal feedback model that represents mutual communication between performers and listeners, including social and cultural contexts.

\subsection{Aims and Research Questions}

The aim of the present study was to investigate what types of communication cues performers or audience members regard as important in multimodal musical interactions. Though empirical studies have indicated that multimodal information influences musical communication, to our knowledge none have used the questionnaire method to assess participants' self-reports on the significance of various music performance cues. We thus 
attempted to elucidate factors to which participants in music performances pay attention. Combining participants' subjective perceptions of multiple cues with empirical findings of actual behavior in music performance would contribute to a deeper understanding of musical communication. In addition, musical interactions may differ between roles (performer and audience members), styles (classical and popular music) (Davidson, 1997; Seddon \& Biasutti, 2009), or situations (practice and actual performance) (Weeks, 1996). We thereby make the following hypotheses. (1) The degree of importance rated by participants differs among cues. (2) the roles of performers or audience members may affect their perceptions of the importance of communication cues; (3) music genre, stage positioning, or situation (practice or performance) may influence people's perception of the importance of communication cues.

\section{Method}

\subsection{Research Design}

We created questionnaire items by extending Davidson's (1997) musical model and communication cues categorized by Daibo (1998). The questionnaires presented simple communication flows and 10 types of cues in music performance. In imagining music performances, participants rated the importance of each cue according to their role (performer/audience), communication flow (sender/receiver), situation (practice/performance). Performers selected the music genres that their performances usually play. Performers were also asked to draw stage positioning in music performance.

\subsection{Participants}

Two hundred thirty-five participants responded to our questionnaires: 86 performers with ensemble experience (29 males and 57 females, $M_{\text {age }}=20.2, S . D .=4.1$ ) and 149 audience members (62 males and 87 females, $M_{\text {age }}=19.0, S . D .=1.2$ ). Performers and audience members were completely separate entities and did not overlap in their roles. Participation was voluntary. All those who participated as performers were either amateur performers or music majors. Performers' individual experiences with musical instruments varied, with an average of 12.1 years of performing experience. The most common musical instrument, played by 21 performers, was piano; the second most common, played by 8 performers, was guitar. The participating performers usually played with an ensemble. We instructed performers who played both ensemble and solo to complete the questionnaire items with reference to ensemble playing behavior. Therefore, while the participants included performers who generally played solo instruments (e.g. piano), all the participants were required to answer items about ensemble playing behavior. Participants responded which music genres they as audience usually listen to. Multiple answers were allowed. The most popular choice was pop music, at $81.2 \%$; the second most popular was classical music, at $37.6 \%$. We excluded two performers and seven audience members from the participant group because we regarded them as unsuitable according to their answers to open-ended responses. This left us with a total of 235 participants.

\subsection{Materials}

We referred to Davidson's (1997) musical model in creating a simple reciprocal communication model in which performers and audience members mutually encode and decode information (Figure 1). Although prior studies have criticized such a simple encode-decode model (e.g., Shannon \& Weaver, 1962) for its lack of context, meaning, or feedback from the receiver, we have employed it because of its advantages, including simplicity, generality, and quantifiability (Chandler, 1994). Our model further simplifies interactions during music performance: performers communicate with co-performers and audience members, while audience members communicate with performers and co-audience members. This model enables us to distinguish between the sender and receiver of a particular signal. We did not employ models that incorporate feedback towards specific behavior, including situational or contextual factors, such as reciprocal feedback model (Hargreaves, MacDonald, \& Miell, 2005), because our goal was to investigate participants' introspection on the importance of communication cues in general. 


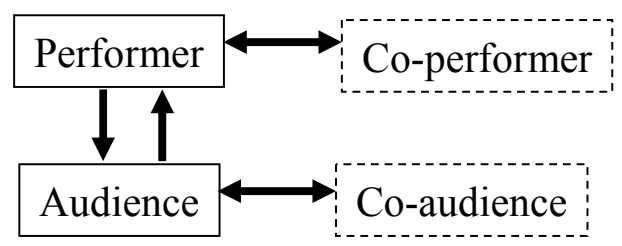

Figure 1. Communication flow in the present study

Communication cues employed in the present study were based on Daibo's (1998) categorization of channels of communication; this categorization was chosen because it incorporates basic communication modes that participants could easily simulate, and because these cues correspond to cues in empirical prior studies cited earlier. We employed the following 10 types of cues: facial expression; gaze; body movement; posture; touch; interpersonal distance; verbal information; attire; breath; musical sound. We added breath (suggested as important by Nakamura (1995)) and musical sounds (suggested as important by many studies, e.g., Juslin (2005)). The item attire was added later on in this study and was consequently rated by only 41 performers and 125 audience members. Table 1 summarizes the questions, whereas the Appendix displays a sample of actual questionnaires used in the present study. Performers and audience members answered each question listed in Table 1 that highlighted the participants' encoding and decoding of communication with their partners. As illustrated in the Appendix, we explained communication flow to the participants through the use of simple figures in the questionnaire.

Table 1. Questionnaire items: The check-marked cues are employed in each communication flow

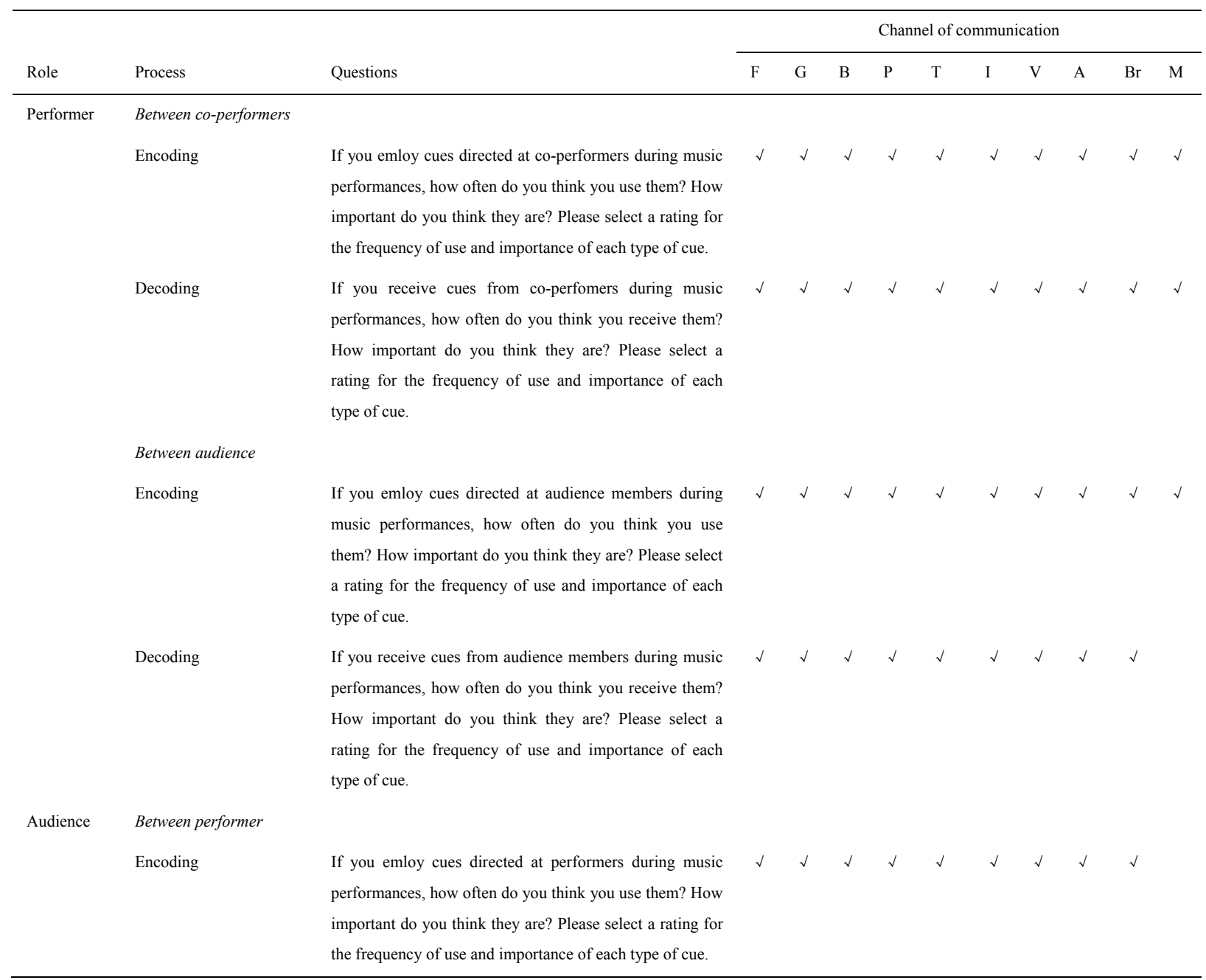




\begin{tabular}{|c|c|c|c|c|c|c|c|c|c|c|c|}
\hline Decoding & $\begin{array}{l}\text { If you receive cues from perfomers during music } \\
\text { performances, how often do you think you receive them? } \\
\text { How important do you think they are? Please select a } \\
\text { rating for the frequency of use and importance of each } \\
\text { type of cue. }\end{array}$ & $\sqrt{ }$ & $\sqrt{ }$ & $\sqrt{ }$ & $\sqrt{ }$ & $\sqrt{ }$ & $\sqrt{ }$ & $\checkmark$ & $\sqrt{ }$ & $\sqrt{ }$ & $\sqrt{ }$ \\
\hline \multicolumn{12}{|c|}{ Between co-audience } \\
\hline Encoding & $\begin{array}{l}\text { If you emloy cues directed at co-audiences during music } \\
\text { performances, how often do you think you use them? How } \\
\text { important do you think they are? Please select a rating for } \\
\text { the frequency of use and importance of each type of cue. }\end{array}$ & $\sqrt{ }$ & $\checkmark$ & $\sqrt{ }$ & $\sqrt{ }$ & $\sqrt{ }$ & $\sqrt{ }$ & $\sqrt{ }$ & $\sqrt{ }$ & $\sqrt{ }$ & \\
\hline Decoding & $\begin{array}{l}\text { If you receive cues from co-audiences during music } \\
\text { performances, how often do you think you receive them? } \\
\text { How important do you think they are? Please select a } \\
\text { rating for the frequency of use and importance of each } \\
\text { type of cue. }\end{array}$ & $\sqrt{ }$ & $\checkmark$ & $\sqrt{ }$ & $\sqrt{ }$ & $\sqrt{ }$ & $\sqrt{ }$ & $\sqrt{ }$ & $\sqrt{ }$ & $\sqrt{ }$ & \\
\hline
\end{tabular}

Note. The types of communication cues rated by participants are as follows: Facial expression (F); Gaze (G); Body movement (B); Posture (P); Touch (T); Interpersonal distance (I); Verbal information (V); Attire (A); Breath (Br); Musical sound (M).

To examine what types of cues were regarded as important, participants were required to imagine music performances and to fill in questionnaires about the communication cues employed in those performances according to their role as performers or audience members (see Appendix). In order to develop survey items, a pilot questionnaire was filled out in advance by our laboratory members. We then improved the questionnaire according to their advice.

Participants rated the importance of each item on a 4-point scale from 0 (unimportant) to 3 (extremely important). Participants were instructed to specify if they thought that they could not actually use or receive a particular signal, and if so to omit the question on the importance of that cue. Performers also selected the music genres that their performances usually play. In order to elucidate the influence of music genres, the 24 participants who selected only classical music were categorized as classical music performers, while the 28 who selected pop, rock, or jazz and avoided classical music were classified as popular music performers. Popular and classical music performers were compared according to this categorization. The remaining participants asserted that their performances covered more than one genre (e.g. classic music and jazz). Finally, to elucidate the performance setups in which they usually play, performers were asked to draw simple charts illustrating their stage positioning for both practices and performances.

\subsection{Procedure}

First, participants were required to fill in a section about personal details, after which they answered the questions. Performers and audience members did not overlap in their roles. They were given sufficient time to complete the questionnaires, which took them 20-30 minutes.

\section{Results}

\subsection{Communication Cues between Performers}

Figure 2 displays the mean ratings of the cues of bidirectional communication. To examine differences among cue ratings, an ANOVA was conducted. In the communication directed at co-performers by performers, significant differences were observed among cues (practice: $F(9,460)=23.307, p<.001, p^{2}=.313$; performance: $F(9,438)=21.071, p<.001, p^{2}=.302$ ). To examine these differences, multiple comparisons were conducted using the R-E-G-W Q-test. A subgroup was formed when no significant differences were demonstrated among the average ratings for two or more cues. In practices, performers rated the cue subgroups in order of importance as follows: 1) sound and breath; 2) gaze and verbal information. In performances, performers rated the cue subgroups as follows: 1) sound, breath, and gaze; 2) gaze and movement. 


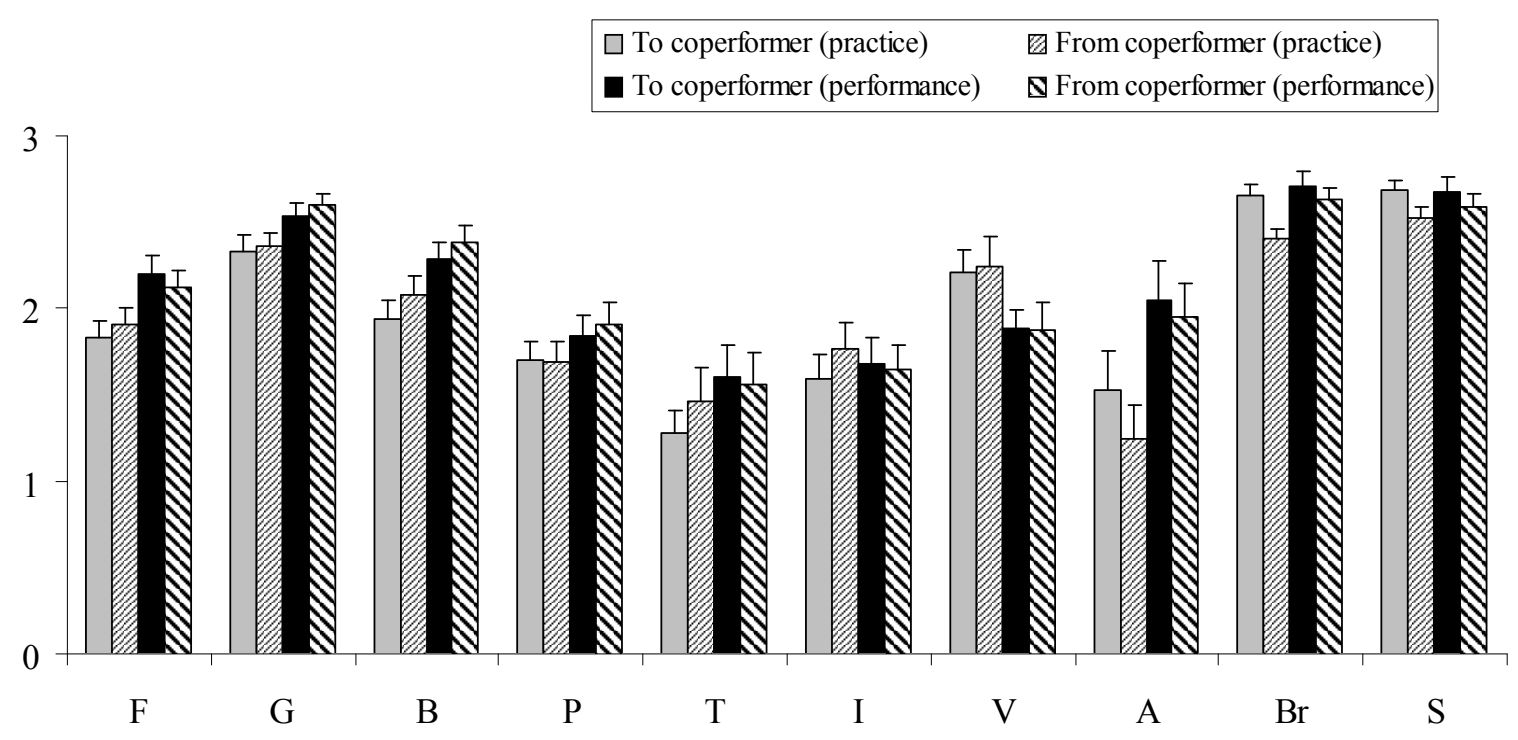

Figure 2. Cues employed for co-performer communication

Note. Error bars represent standard errors

Significant differences were observed in the communication from co-performers to performers (practice: $F$ ( 9 , $495)=14.412, p<.001, p^{2}=.208$; performance: $\left.F(9,434)=16.451, p<.001, p^{2}=.254\right)$. The results of multiple comparisons were as follows. In practices, the performers rated sound, breath, gaze, and verbal information as the most important subgroup of cues. In performances, the participants rated breath, gaze, sound, and movement as the most important subgroup of cues.

With respect to differences between the two genres, a t-test was conducted in order to examine differences among cue ratings. The following cues were found to differ in information directed at co-performers by performers: Facial expressions $\left(M_{C}=1.76, M_{P}=2.32, t(41)=2.355, p<.05, d=.718\right)$ and body movements $\left(M_{C}\right.$ $\left.=1.43, M_{P}=2.21, t(36)=3.008, p<.01, d=1.012\right)$ in practices, and facial expressions $\left(M_{C}=1.94, M_{P}=2.57\right.$, $t(38)=2.530, p<.05, d=0.809)$ and touch $\left(M_{C}=1.00, M_{P}=1.90, t(9)=2.862, p<.05 d=1.001\right)$ in performances ( $M_{C}$ : mean rating of classical music performers; $M_{P}$ : mean rating of popular music performers). However, touch was excluded from the following discussion because only three classical musicians referred to it - a ratio too small for statistical analysis. The communication from co-performers to performers was therefore not found to significantly differ between genres.

\subsection{Communication Cues between Performers and Audience Members}

Figure 3 represents the mean values of the cues through which performers and audience members communicate. First, in the communication flow from performers to audience members, the importance of the cues rated by performers was significant $\left(F(9,350)=14.942, p<.001, p^{2}=.278\right)$. Multiple comparisons showed that the subgroup that obtained the highest rating incorporated the musical sound cue only. Facial expressions were regarded as the second most important form of information directed at audience members by performers, and the second subgroup consisted of cues except for sound. None of the cues showed a significant difference between genres.

The importance of the cues received by audience members was also significant $\left(F(9,934)=28.786, p<.001, p^{2}\right.$ $=.217$ ). Multiple comparisons demonstrated that, similarly to performers' (i.e. senders') ratings, the subgroup that obtained the highest rating incorporated the musical sound cue only. The second most highly rated subgroup contained facial expression, verbal information, and body movement.

In communication from audience members to performers, the importance of the cues used by audience members to direct information was significant $\left(F(8,604)=13.531, p<.001, p^{2}=.152\right)$. Multiple comparisons showed that audience members regarded gaze, body movement, breath, and verbal information as the most important cues through which to interact with performers. 
The importance of the cues received by performers was also significant (ANOVA, $F(8,282)=6.198, p<.001$, $p^{2}=.150$ ). Multiple comparisons demonstrated that performers regarded audience members' facial expression, verbal information, and gaze as most important. The importance of body movements was significantly higher for popular music performers than for classical music performers $\left(M_{C}=1.42, M_{P}=2.20, t(30)=2.393, p<0.05\right.$, $d=0.874)$.

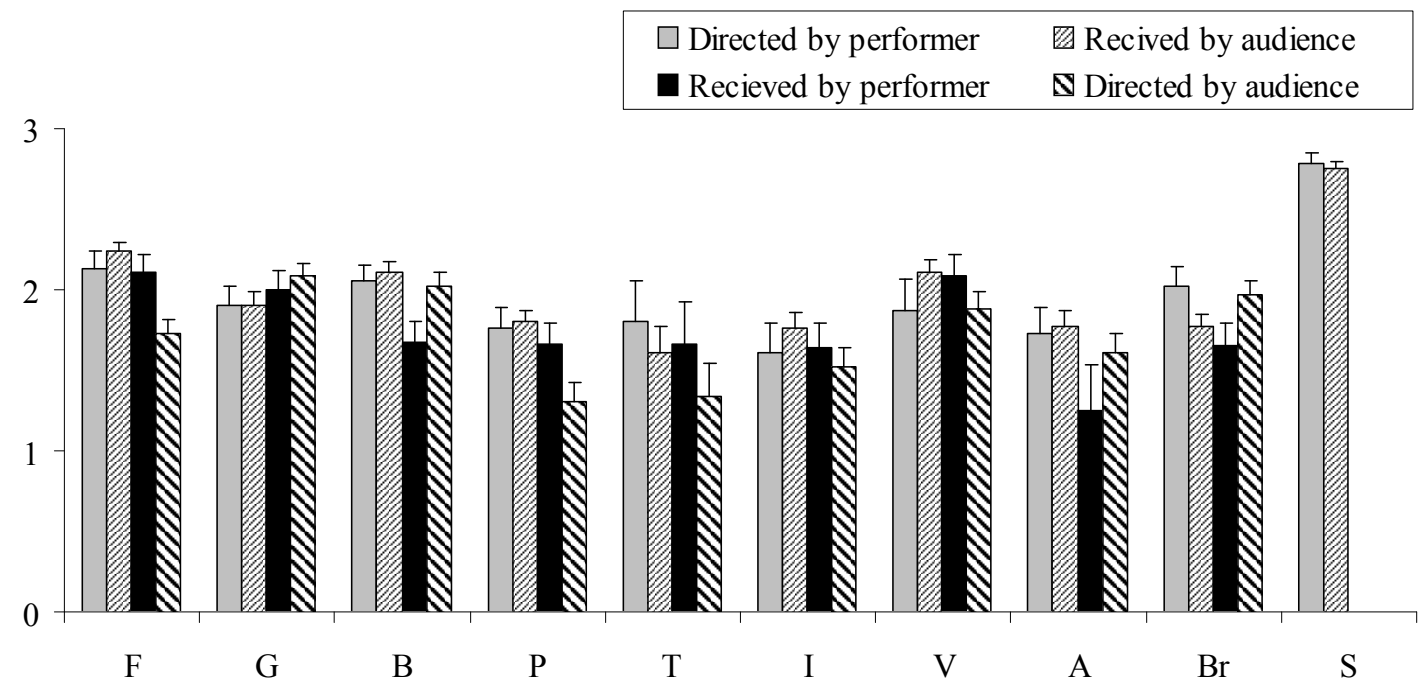

Figure 3. Communication cues employed for performer-audience communication

\subsection{Communication Cues between Audience Members}

Figure 4 shows the mean value of the information directed at and received by the audience members. The importance of the cues directed by audience members toward co-audience members was significant (ANOVA, $F$ $\left.(8,461)=6.399, p<.001, p^{2}=.100\right)$. Multiple comparisons showed that the most highly rated subgroup incorporated breath, body movement, facial expression, and attire. The importance of the cues through which information was received from co-audience members was also significant (ANOVA, $F(8,555)=5.938, p<.001$, $p^{2}=.079$ ). Multiple comparisons indicated that the most highly rated subgroup included all cues other than gaze, interpersonal distance, and touch.

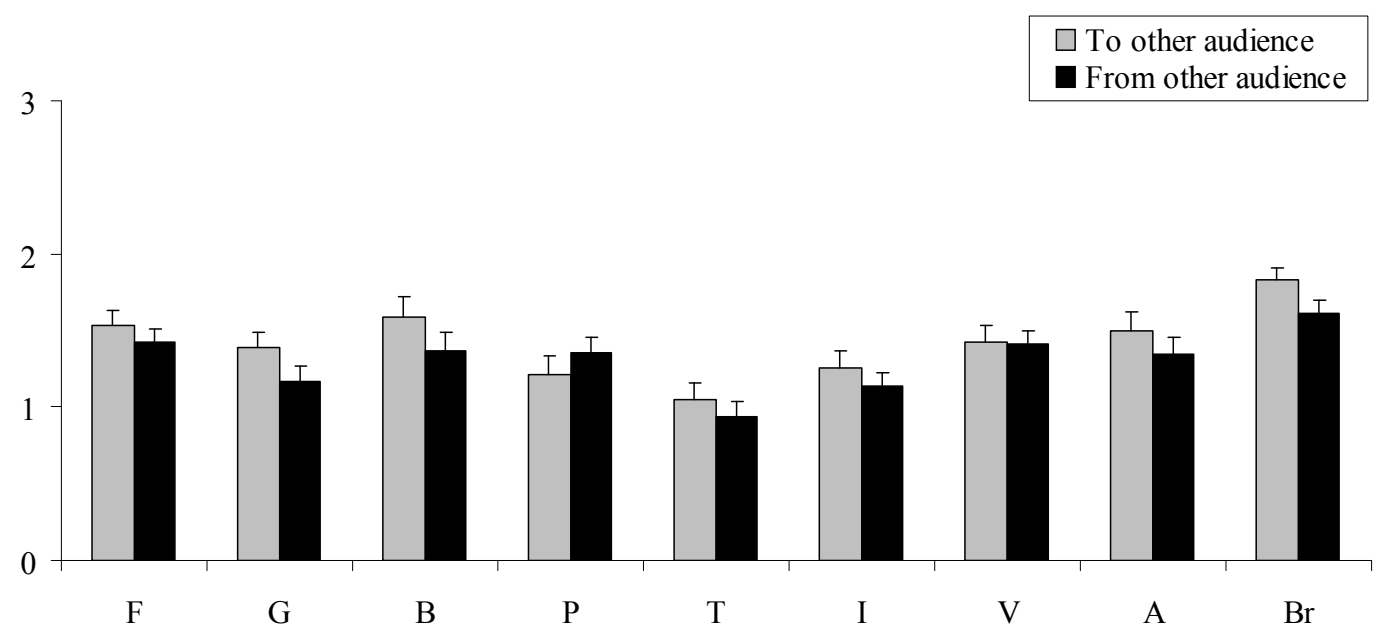

Figure 4. Cues employed for inter-audience communication 


\subsection{Correlation between Cues that Obtained Importance}

The Pearson's product-moment correlation coefficients between communication processes were calculated using the participants' average ratings (Table 2). With respect to performers, the highest correlation existed in inter-performer communication during performances, at .98. All of the correlations between the information that they received from audience members and other types of information were low. As to audience members, the average correlation was the highest regarding information communicated among them, although the average correlation was not as high as that of communication among performers. The correlations between the ratings of performers and audience members demonstrated that the correlation between cues through which performers directed information toward audience members and cues through which audience members received information from performers was the highest, at .90. The reverse correlation-between cues through which audience members directed information toward performers and through which performers received information from audience members - was lower.

Table 2. Correlations between communication processes

\begin{tabular}{|c|c|c|c|c|c|c|c|c|c|c|}
\hline & 1 & 2 & 3 & 4 & 5 & 6 & 7 & 8 & 9 & 10 \\
\hline 1. Performer-> Co-performer (practice) & - & & & & & & & & & \\
\hline 2. Performer $<-$ Co-performer (practice) & $.94 * * *$ & - & & & & & & & & \\
\hline 3. Performer- $>$ Co-performer (performance) & $.87 * *$ & $.75^{*}$ & - & & & & & & & \\
\hline 4. Performer<- Co-performer (performance) & $.86^{* *}$ & $.78^{* *}$ & $.98 * * *$ & - & & & & & & \\
\hline 5. Performer-> Audience & $.68^{*}$ & $.64 *$ & $.70^{*}$ & $.65^{*}$ & - & & & & & \\
\hline 6. Performer $<-$ Audience & .42 & .64 & .17 & .20 & .51 & - & & & & \\
\hline 7. Audience->Performer & $.82 * *$ & $.81^{* *}$ & $.82 * *$ & $.83^{* *}$ & .62 & .39 & - & & & \\
\hline 8. Audience<-Performer & .59 & .60 & .53 & .50 & $.90 * * *$ & .66 & .54 & - & & \\
\hline 9. Audience->Co-audience & $.73 *$ & .54 & $.84 *$ & $.77^{*}$ & .65 & .02 & $.73 *$ & .43 & - & \\
\hline 10. Audience $<$-Co-audience & $.67^{*}$ & .46 & .63 & .58 & .55 & .08 & .47 & .48 & $.86^{* *}$ & - \\
\hline
\end{tabular}

\subsection{Stage Positioning and Music Genre in Performance}

We compared the stage positioning in the two different music genres and analyzed participants' responses regarding it. The data for performers' positions were limited (17 classic performers and 22 popular music performers), and consequently, we could not conduct statistical comparisons. On the basis of the charts drawn by participants, stage positioning could be classified into two main types: inward (where performers face each other) and forward (where the all performers face the same direction). In the forward position, there is a point that certain performers gaze at, while for others, there is no specific point. Table 3 shows performers' positioning by music genre in both practices and performances. A remarkable difference can be observed between classical and popular music performers in positioning during performances. Classical music performers are often positioned so that they can gaze at a particular object (the conductor or a metronome), both in practices and performances. In contrast, popular music performers place themselves in an inward position during practices and a forward position during performances.

Table 3. Positioning according to music genre in both practice and performances, AP represents "attention points"

\begin{tabular}{|c|c|c|c|c|c|c|}
\hline & \multicolumn{3}{|c|}{ Classic } & \multicolumn{3}{|c|}{ Pop } \\
\hline & \multirow[t]{2}{*}{ Inward } & \multicolumn{2}{|c|}{ Forward } & \multirow[t]{2}{*}{ Inward } & \multicolumn{2}{|c|}{ Forward } \\
\hline & & $\mathrm{AP}$ & No AP & & AP & No AP \\
\hline Practice & 6 & 9 & 1 & 18 & 1 & 2 \\
\hline Performance & 2 & 9 & 6 & 0 & 2 & 18 \\
\hline
\end{tabular}




\section{Discussion}

The present study was designed to investigate the rated importance of multimodal communication cues in inter-performer, performer-audience, and inter-audience communication during music performances. The responses to our questionnaires elucidated the following results. (1) Participants' roles as either performers or audience members affected their opinions about the importance of communication cues. In inter-performer communication, sound, gaze, body movement, facial expression, and breath were rated as highly important in both practice and performance. In performer-to-audience communication, sound, facial expression, and body movement were rated as highly important. (2) Participants regarded similar cues as important regardless of their role: senders and receivers of inter-performer and performer-to-audience communication. (3) Music genre (classical or popular) and situation (practice or performance) influenced participants' opinions about the importance of communication cues and stage positioning.

The importance of particular communication cues differed between performers and audience members. Figure 5 draws the summary of this research, which provides a fundamental perspective on the interaction between participants in music performance. To summarize the results regarding communication among participants, we selected those cues in first or second subgroups whose mean importance rating was above 2 . This represents the components regarded as important by the participants.

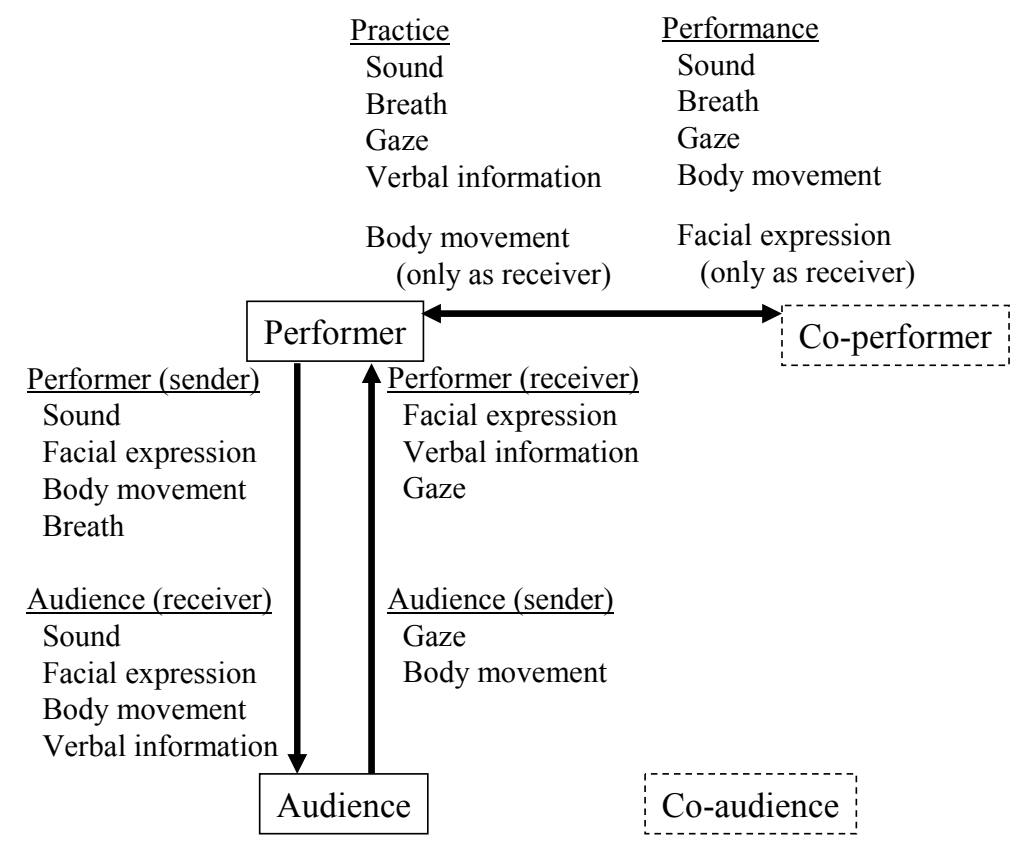

Figure 5. Communication cues regarded as important

\subsection{Cues between Performers that Were Deemed Important}

Performers regarded sound as the most important cue of communication with co-performers. This result is in line with prior findings on the significant role of audio cues during ensemble performances (Keller \& Appel, 2010; Loehr et al., 2011). One of the possible explanations for the dominance of the audio cue in inter-performer communication is that auditory information is prioritized over visual information in terms of synchronization among performers while playing pieces without significant temporal changes (Repp \& Penel, 2002). Another possible explanation for the importance of sound is that the coordination of sound is likely to be the most essential requirement for ensemble performance.

Gaze, body movement, and facial expression were also regarded as important cues for inter-performer communication. These results are consistent with prior empirical findings, which stated that visual cues such as gaze (Kawase, 2014; Moran, 2010; Williamon \& Davidson, 2002) and body movement (Goebl \& Palmer, 2009; Keller, 2012; Luck \& Toiviainen, 2006) enhanced ensemble coordination. The present results suggest that 
performers are quite conscious of utilizing these visual cues not only in actual performance, but also in their approach to performance cues.

Another notable tendency among the participants was for performers to regard breath as very important, although prior studies have rarely focused on it or rarely specified whether performers intentionally or unintentionally synchronize their breathing. Meanwhile, the present study revealed that performers take respiratory cues into consideration. One of the possible reasons for why breath cue obtained a high value may be the influence of a traditional Japanese idiom, 'iki ga au' or 'aun no kokyu', which means 'breathe at the same time/synchronize breathing'. This idiom is used to describe people synchronizing their actions and feelings with others, to mean performing in harmony in reference to acting or playing music. The phrase is not merely an idiom. Indeed, breathing does synchronize when performers start playing together after a long pause in music performance (Nakamura, 1995). Kawase and Nakamura (2007) found that participants synchronized their breathing when communicating through drums. Likewise, breathing synchronizes in dyads during spontaneous conversation (McFarland, 2001). Given that the concept of 'synchronized breathing' has a substantial influence not only on music performance but also on joint action in Japan, it would be fruitful to explore whether music participants with different cultural backgrounds also regard breath as an important communication cue. Furthermore, given that some scores comprise breath marks, performers may be inclined to pay attention to breathing.

\subsection{Cues between Performers and Audiences that Were Deemed Important}

In performer-audience communication, the fact that sound alone obtained especially high importance regardless of the role of the evaluator as sender or receiver is in line with the prior finding that sound conveys performers' intention to audience members (e.g., Juslin, 2001). Yet, this result contradicts other studies that suggest that, under audio-visual conditions, visual information more significantly affects the conveyance of performers' intention than does auditory information (Ohgushi, 2005; Platz \& Kopiez, 2012), or that visual cues considerably influence audience members' decoding, including body movement (e.g., Dahl \& Friberg, 2007), posture (e.g., VanWeelden, 2002), facial expression (e.g.,Wöllner, 2008), and gaze (Antonietti, Cocomazzi, \& Iannello, 2009). Namely, visual information significantly influenced actual behavior, even though participants were not conscious of it. This result thus provides a possibility that participants' thoughts differ from their actual behavior. This could be supported by Kawase's (2014) studies on synchronization during piano duo performances, which indicated that performers' subjective responses did not always reflect their actual behavior.

Facial expression was regarded as important by both performers and audience members in performer-audience communication. This may account for the fact that facial expression can convey emotion during music performance (Ohgushi \& Hattori, 1996; Thompson, Russo, \& Quinto, 2008). As many studies have indicated that music performance and its appreciation are firmly associated with emotion (e.g., Juslin \& Sloboda, 2001), participants might think that facial expression that represents emotion is one of the key aspects of playing and listening to music. Owing to the close relationship between facial expression and emotion (Ekman, 1975), participants might also believe that facial expression represents the state of audience members' emotional feedback to performers. For example, audiences' appraisal of performances might show in their facial expressions: if they like a performance, they might smile; if they do not, they might appear bored.

Verbal information was regarded as important by both pefromers and audience members when receiving information. Since little has been reported regarding verbal information interaction in performer-audience communication, we can only surmise about the significance of verbal cues. From an empirical perspective, it can be inferred that audience members might consider verbal interaction to be a form of mutual feedback with performers. For example, popular music performers frequently appeal to audience members through verbal cues, while audience members cheer during excellent performances. The present study suggests the potential importance of verbal interaction in performer-audience communication, even though talking is not allowed in some situations due to performance etiquette.

Communication among audience members was less significant than that among all of the other participant relationships. Breath was the most important cue both sent and received by audience members. As mentioned earlier, this phenomenon may reflect the fact that breath is believed to play a key role in joint actions such as synchronization in Japan.

\subsection{Reciprocal Flows of Cues among Participants that Were Deemed Important}

Similar cues were rated as important regardless of the direction of communication flow in both inter-performer and performer-to-audience interactions, as shown by their high correlation and similar cue ratings. In inter-performer communication, performers considered sound and breath most important, and gaze second most 
important, when sending and receiving information in both practices and performances. In performer-audience communication, both performers and audience members regarded sound as the most important cue and facial expression as the second most important. The result that both senders and receivers regarded similar cues as important may mean that they pay attention to similar cues. It is difficult to specify that this is reciprocal interaction because the present study did not account for instant feedback in a particular musical situation. However, at least on a conceptual level, communication through similar cues may be smoother than through different cues, although this presumption needs to be examined.

\subsection{Unidirectional Flows of Cues among Participants that Were Deemed Important}

Despite the similarity in cue importance in inter-performer and performer-to-audience communication, we observed differences between senders and receivers of audience-to-performer and inter-audience communication. The correlation coefficient between sending audience members and receiving performers was lower than that of the reverse relationship. In addition, performers and audience members differed in their choices of the most important cue (audience members regarded gaze and body movement as important, whereas performers regarded facial expression and verbal information as important). These results suggest that audience members thought some cues worthwhile, while performers thought them worthless, and vice verse. Thus, participants might not be able to completely understand what performers or audience members want to convey to each other.

\subsection{Influences of Music Genre and Practice/Performance on Cues that Were Deemed Important and on Stage Positioning}

Music genres altered performers' perception of the importance of various cues. This can be explained by the finding that performance etiquette varies among genres (e.g. Seddon \& Biasutti, 2009). In both inter-performer and performer-audience communication, popular music performers regarded nonverbal information as more important than classical music performers did. In performer-audience communication, popular music performers also regarded audience members' movement as more important than classical music performers did. In practices, popular music performers asserted that they played in a more inward position, which provided views of the other performers, than did classical music performers. In performances, popular music performers said that they looked toward audience members, whereas classical music performers said that they frequently looked toward a person or object such as a conductor. As popular music performers have fewer restrictions during performances (Davidson, 1997), they might think that they can engage in more varied communication, or they might be more sensitive to nonverbal behavior compared with their classical music counterparts.

Cue importance in inter-performer communication was shown to differ between practices and performances. This result parallels the prior finding that interactions that arise in practices are hidden from the audience during performances (Weeks, 1996). Sound, breath, and gaze were rated highest in performances, whereas gaze directed at co-performers was rated the second highest in practices. Subsequently, verbal information in practices and body movement and facial expressions in performances obtained a higher significance. The importance of verbal interaction (Ginsborg et al., 2006) may be one of the salient discrepancies between practices and performances. Due to performance etiquette, performers refrain from exchanging information verbally specifically in performances of classical music. Hence, in the absence of verbal cues, the importance of nonverbal cues such as body movement increases in performances. These differences between practices and performances suggest that the alternation of the relationships between communication cues changes people's perspectives on communication strategy.

\section{Future Studies}

Multiple musical communication cues which empirical studies rarely explored require to be examined in future studies. The present study elucidated that participants in music performance regard cues, such as breathing or gaze, as important. However, most empirical studies ignore the roles of such cues. It is thus necessary to speculate about how and why performers and audience members regard them as important.

One limitation of the present study derives from the discrepancy between participants' intentions and their actual behavior. Some non-verbal communication could occur in cases that do not relate to communication with other people; these forms of non-verbal communication emerge even if other people either do not exist or are not seen (e.g. Iverson \& Goldin-Meadow, 1998; Rimé, 1982). The performers also may act in a manner that suggests they are communicating with co-performers on-stage, even though they do not actually intend to communicate. These phenomena indicate the possibility of unintentional behavior. Consequently, caution must be exercised in speculating the association between participants' thoughts and behavior in actual music performance. 
Another limitation of the present study arises from the absence of perspectives on the differences among performance types or styles. A difference in performance type can alter the setting of a performance, so the corresponding communication modes may also change. The use of particular instruments might also affect performers' viewpoints on communication cues. For example, pianists (who were the largest group in this study) cannot use interpersonal distance and have to place their hands on the keyboard. Conversely, vocalists can perform more freely on stage and are less physically constrained than instrumental performers are. Further, the influence of genre remains to be determined. For example, jazz musicians may interact with co-performers in unique ways when improvising in their performance compared with performers of popular music. These issues need to be examined in future research.

\section{Acknowledgments}

We appreciate Dr. Irène Deliège's great support. We would also like to thank Dr. Alexandra Lamont for proof reading of the draft and helpful comments and express our gratitude to Dr. Andreas Lehmann for his valuable comments. We wish to thank Dr. Toshie Nakamura and every member of Nakamura's Lab for excellent support. Thanks go to Kei Eguchi for great support. We would also like to extend thanks the editor and anonymous reviewers for valuable comments. The research was partially funded by the Fieldwork Support Project, Graduate School of Human Sciences, Osaka University.

\section{References}

Antonietti, A., Cocomazzi, D., \& Iannello, P. (2009). Looking at the audience improves music appreciation. Journal of Nonverbal Behavior, 33, 89-106. http://dx.doi.org/ 10.1007/s10919-008-0062-x

Chandler, D. (1994). The transmission model of communication. Retrieved March 6, 2014, from http://www.aber.ac.uk/media/Documents/short/trans.html

Dahl, S., \& Friberg, A. (2007). Visual perception of expressive in musicians' body movement. Music Perception, 24, 433-454. http://dx.doi.org/10.1525/mp.2007.24.5.433

Daibo, I. (1998). Bodily Communication: How do people communicate their closeness to each other? Science Publisher, Tokyo (in Japanese).

Davidson J. W. (1993). Visual perception of performance manner in the movement of solo musicians. Psychology of Music, 21, 103-113. http://dx.doi.org/10.1177/030573569302100201

Davidson, J. W. (1997). The social in musical performance. In D. J. Hargreaves, \& A. C. North (Eds.), The Social Psychology of Music (pp. 209-228). Oxford University Press, New York.

Ekman, P., \& Friesen, V. W. (1975). Unmasking the face. Prentice-Hall, Englewood Cliffs, N.J.

Gabrielsson, A., \& Juslin, P. N. (1996). Emotional expression in music performance: Between the performer's intention and the listener's experience. Psychology of music, 24, 68-91. http://dx.doi.org/10.1177/0305735696241007

Ginsborg, J., Chaffin, R., \& Nicholson, G. (2006). Shared performance cues in singing and conducting: A content analysis of talk during practice. Psychology of Music, 34, 167-194. http://dx.doi.org/10.1177/0305735606061851

Ginsborg, J., \& King, E. (2012). Rehearsal talk: Familiarity and expertise in singer-pianist duos. Musicae Scientiae, 16, 148-167. http://dx.doi.org/10.1177/1029864911435733

Goebl, W., \& Palmer, C. (2009). Synchronization of timing and motion among performing musicians. Music Perception, 26, 427-438. http://dx.doi.org/10.1525/mp.2009.26.5.427

Griffiths, N., \& Davidson, J. (2006). The effects of concert dress and physical appearance on perceptions of female solo performers. Proceedings of 9th International Conference on Music Perception and Cognition, $1723-1726$.

Hargreaves, D.J., MacDonald, R., \& Miell, D. (2005) How do people communicate using music? In Miell, D., MacDonald, R., and Hargreaves, D.J. (Eds.). Musical Communication (pp. 1-25). Oxford University Press, New York.

Hubbard, T. L. (2010). Auditory imagery: Empirical findings. Psychological bulletin, 136, 302-329. http://dx.doi.org/10.1037/a0018436

Iverson, J. M., \& Goldin-Meadow, S. (1998). Why people gesture when they speak. Nature, 396, 228-228. http://dx.doi.org/10.1038/24300 
Juslin, P. N. (2001). Communicating emotion in music performance: a review and theoretical framework. In P. N. Juslin, \& J. A. Sloboda, (Eds.). Music and emotion; theory and research (pp. 309-337). Oxford University Press, New York.

Juslin, P. N. (2005). From mimesis to catharsis: Expression, perception, and induction of emotion in music. In D. Miell, R. MacDonald, \& D. J.Hargreaves (Eds.), Musical Communication (pp. 85-115). Oxford University Press, New York.

Juslin, P. N., \& Sloboda, J. A. (2001). Music and emotion: Theory and research. Oxford University Press.

Kawase, S. (2009) An exploratory study of gazing behavior during live performance. Proceedings of 7 th Triennial Conference of European Society for the Cognitive Sciences of Music, 227-232.

Kawase, S. (2013). Factors influencing audience seat selection in a concert hall: A comparison between music majors and nonmusic majors. Journal of Environmental Psychology, 36, 305-315. http://dx.doi.org/10.1016/j.jenvp.2013.08.002

Kawase, S. (2014). Gazing behavior and coordination during piano duo performance. Attention, Perception, \& Psychophysics, 76, 527-540. http://dx.doi.org/10.3758/s13414-013-0568-0

Kawase, S., \& Nakamura, T. (2007). Interpersonal interaction using drums as a mean of communication: A kansei information study. Bulletin of Graduate School of Human Sciences, Osaka University, 165-188.

Keller, P. E. (2012). Mental imagery in music performance: Underlying mechanisms and potential benefits. Annals of the New York Academy of Sciences, 1252, 206-213. http://dx.doi.org/10.1111/j.1749-6632.2011.06439.x

Keller, P. E., \& Appel, M. (2010). Individual differences, auditory imagery, and the coordination of body movements and sounds in musical ensembles. Music Perception, 28, 27-46. http://dx.doi.org/10.1525/mp.2010.28.1.27

Keller, P. E., Knoblich, G., \& Repp, B. H. (2007). Pianists duet better when they play with themselves: On the possible role of action simulation in synchronization. Consciousness and Cognition, 16, 102-111. http://dx.doi.org/10.1016/j.concog.2005.12.004

Kendall, R. A., \& Carterette, E. C. (1990). The communication of musical expression. Music Perception, 8 , 129-163.

Krahé, C., Hahn, U., \& Whitney, K. (2013). Is seeing (musical) believing? The eye versus the ear in emotional responses to music. Psychology of Music. http://dx.doi.org/10.1177/0305735613498920

Loehr, J. D., Large, E. W., \& Palmer, C. (2011). Temporal coordination and adaptation to rate change in music performance. Journal of Experimental Psychology: Human Perception and Performance, 37, 1292-1309. http://dx.doi.org/10.1037/a0023102

Luck, G., \& Toiviainen, P. (2006). Ensemble musicians' synchronization with conductors' gestures: an automated feature-extraction analysis. Music Perception, 24, 189-200. http://dx.doi.org/10.1525/mp.2006.24.2.189

Maduell, M., \& Wing, A. M. (2007). The dynamics of ensemble: the case for flamenco. Psychology of Music, 35, 591-627. http://dx.doi.org/10.1177/0305735607076446

McFarland, D. H. (2001). Respiratory Markers of Conversational Interaction. Journal of Speech, Language, and Hearing Research, 44, 128-143. http://dx.doi.org/10.1044/1092-4388(2001/012)

Moran, N. (2010). Improvising musicians' looking behaviours: Duration constants in the attention patterns of duo performers. Proceedings of the 11th International Conference on Music Perception and Cognition, 565-568.

Nakamura, T. (1987). The communication of dynamics between musicians and listeners through musical performance. Perception and Psychophysics, 41, 523-533. http://dx.doi.org/10.3758/BF03210487

Nakamura, T. (1995). Ma ni okeru ensousha to bansousha no kokyuu no douki (Performer's respiration synchronization with accompanist on Ma). The 59th Annual Convention of Japanese Psychological Association, 631 (in Japanese).

Ohgushi, K. (2005). Interaction between auditory and visual information in conveyance of players' intentions. Journal of the Acoustical Society of Japan, 61, 284-288. 
Ohgushi, K., \& Hattori, M. (1996). Emotional communication in performance of vocal music-interaction between auditory and visual information. Proceedings of the 4th ICMPC, 269-274.

Palmer, C. (2013). Music performance: Movement and coordination. In D. Deutsch (Ed.), The psychology of music (3rd ed., pp. 405-422). Amsterdam, The Netherlands: Elsevier.

Pecenka, N., \& Keller, P. E. (2011). The role of temporal prediction abilities in interpersonal sensorimotor synchronization. Experimental Brain Research, 211, 505-515. http://dx.doi.org/10.1007/s00221-011-2616-0

Platz, F., \& Kopiez, R. (2012). When the eye listens: A meta-analysis of how audio-visual presentation enhances the appreciation of music performance. Music Perception, 30, 71-83. http://dx.doi.org/10.1525/mp.2012.30.1.71

Repp, B. H., \& Penel, A. (2002). Auditory dominance in temporal processing: New evidence from synchronization with simultaneous visual and auditory sequences. Journal of Experimental Psychology: Human Perception and Performance, 28, 1085-1099. http://dx.doi.org/10.1037/0096-1523.28.5.1085

Rimé, B. (1982) The elimination of visible behaviour from social interactions: Effects on verbal, nonverbal and interpersonal variables. European Journal of Social Psychology, 12, 113-129. http://dx.doi.org/10.1002/ejsp.2420120201

Seddon, F., \& Biasutti, M. (2009). A comparison of modes of communication between members of a string quartet and a jazz sextet. Psychology of Music, 37, 395-415. http://dx.doi.org/10.1177/0305735608100375

Shannon, C. E., \& Weaver, W. (1962). The mathematical theory of communication. University of Illinois Press, Urbana.

Thompson, W. F., \& Russo, F. A. (2007). Facing the music. Psychological Science, 18, 756-757. http://dx.doi.org/10.1111/j.1467-9280.2007.01973.x

Thompson, W. F., Russo, F. A., \& Quinto, L. (2008). Audio-visual integration of emotional cues in song. Cognition and Emotion, 22, 1457-1470. http://dx.doi.org/10.1080/02699930701813974

Van Weelden, K. (2002). Relationships between perceptions of conducting effectiveness and ensemble performance. Journal of Research in Music Education, 50, 165-176. http://dx.doi.org/10.2307/3345820

Vines, B. W., Krumhansl, C. L., Wanderley, M. M., Dalca, I. M., \& Levitin, D. J. (2011). Music to my eyes: Cross-modal interactions in the perception of emotions in musical performance. Cognition, 118, 157-170. http://dx.doi.org/10.1016/j.cognition.2010.11.010

Wapnick, J., Mazza, J. K., \& Darrow, A. (1998) Effect of performer attractiveness, stage behavior, and dress on violin performance evaluation. Journal of Research in Music Education, 46(Winter), 510-521. http://dx.doi.org/10.2307/3345347

Weeks, P. (1996). A Rehearsal of a Beethoven Passage: An Analysis of Correction Talk. Research on Language and Social Interaction, 29, 247-290. http://dx.doi.org/10.1207/s15327973rlsi2903_3

Williamon, A., \& Davidson, J.W. (2002). Exploring co-performer communication. Musicae Scientiae, 6, 53-72. http://dx.doi.org/10.1177/102986490200600103

Wöllner, C. (2008). Which part of the conductor's body conveys most expressive information? A spatial occlusion approach. Musicae Scientiae, 12, 249-272. http://dx.doi.org/10.1177/102986490801200204

\section{Appendix}

\section{A sample of the questionnaire form for performers (original forms was written in Japanese)}

Question: What types of cues, as indicated below, do you utilize toward your co-performers (e.g. band members) during music performances? How important do you think they are?

Please indicate the appropriate rating.

Note: If you are not able to employ a particular cue, please select "unable to use". For example, if you think you are not able to use facial expression because your face is hidden, please select "unable to use". If you mark an item "not used at all" or "unable to use at all", please do not rate the importance of that item. 


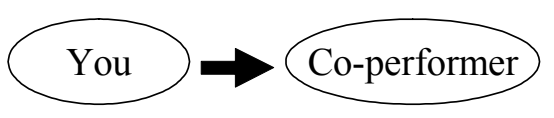

\section{Audience}

\section{$\underline{\text { In practices }}$}

Facial expression (e.g. smiling)

( very frequently $\cdot$ frequently $\cdot$ occasionally)

(do not use at all $\cdot$ unable to use at all)

(extremely important $\cdot$ very important $\cdot$ slightly important $\cdot$ unimportant)

Gaze (e.g. eye contact)

( very frequently $\cdot$ frequently $\cdot$ occasionally)

(do not use at all $\cdot$ unable to use at all)

(extremely important $\cdot$ very important $\cdot$ slightly important $\cdot$ unimportant)

Body movement (e.g. give a cue by moving an arm or jumping)

( very frequently $\cdot$ frequently $\cdot$ occasionally)

(do not use at all $\cdot$ unable to use at all)

(extremely important $\cdot$ very important $\cdot$ slightly important $\cdot$ unimportant)

Posture (e.g. play with the head bent forward)

(very frequently $\cdot$ frequently $\cdot$ occasionally)

(do not use at all $\cdot$ unable to use at all)

(extremely important $\cdot$ very important $\cdot$ slightly important $\cdot$ unimportant)

Touch (touch your co-performer)

(very frequently $\cdot$ frequently $\cdot$ occasionally)

(do not use at all $\cdot$ unable to use at all)

(extremely important $\cdot$ very important $\cdot$ slightly important $\cdot$ unimportant)

Interpersonal distance (e.g. move closer to other people)

( very frequently $\cdot$ frequently $\cdot$ occasionally)

(do not use at all $\cdot$ unable to use at all)

(extremely important $\cdot$ very important $\cdot$ slightly important $\cdot$ unimportant)

\section{Verbal information}

( very frequently $\cdot$ frequently $\cdot$ occasionally)

(do not use at all $\cdot$ unable to use at all)

(extremely important $\cdot$ very important $\cdot$ slightly important $\cdot$ unimportant) 
Attire (your own cloth)

( very frequently $\cdot$ frequently $\cdot$ occasionally)

(do not use at all $\cdot$ unable to use at all)

(extremely important $\cdot$ very important $\cdot$ slightly important $\cdot$ unimportant)

Breath (e.g. synchronize breath)

( very frequently $\cdot$ frequently $\cdot$ occasionally)

(do not use at all $\cdot$ unable to use at all)

(extremely important $\cdot$ very important $\cdot$ slightly important $\cdot$ unimportant)

\section{Musical sound}

( very frequently $\cdot$ frequently $\cdot$ occasionally)

(do not use at all $\cdot$ unable to use at all)

(extremely important $\cdot$ very important $\cdot$ slightly important $\cdot$ unimportant)

\section{Copyrights}

Copyright for this article is retained by the author(s), with first publication rights granted to the journal.

This is an open-access article distributed under the terms and conditions of the Creative Commons Attribution license (http://creativecommons.org/licenses/by/3.0/). 